\title{
Comparison of Antibiotic Sensitivity Pattern of Escherichia coli which Produce Extended Spectrum Beta-Lactamase Strains Isolated from Various Clinical Specimens in Intensive Care Unit
}

\author{
Tuğba Cebeciํㄹ Dilek Keskin², Ahmet Ali Gökal ${ }^{3}$ \\ ${ }^{1}$ Giresun University, Espiye Vocational High School, Department of Medical Services and Techniques, Giresun, Turkey \\ ${ }^{2}$ Adnan Menderes University, Kosk Vocational High School, Department of Food Processing, Aydın, Turkey \\ ${ }^{3}$ Private Giresun Ada Hospital, Department of Infectious Diseases and Clinical Microbiology, Giresun, Turkey
}

Received: 13 February 2019, Accepted: 04 April 2019, Published online: 28 April 2019

(C) Ordu University Institute of Health Sciences, Turkey, 2019

\begin{abstract}
Objective: A retrospective analysis of the widely used antibiotics all susceptibility testing results from Escherichia coli (E. coli) cultured from clinical specimens' private hospital (from January 2017 to November 2018) was performed.

Methods: The VITEK 2 Compact automated microbiology system (bioMérieux) is designed for automated rapid antimicrobial susceptibility testing and identification of clinically relevant bacteria. Minimum inhibitory concentration (MIC) results previously obtained in recent clinical isolates with well-defined in isolates with well-characterized resistance mechanisms with the microdilution method were re-interpreted for the susceptible, intermediate and resistant categories using the 2018 EUCAST breakpoints. Clinical samples are most commonly isolated from blood, sputum and urine samples.

Results: The results of resistance pattern of E. coli isolates in our locality to antimicrobial agents showed that the $64 \mathrm{E}$. coli strains tested against fifteen antimicrobial agents. E. coli isolates were highly resistant to piperacillin, ceftazidime and aztreonam $98 \%, 61 \%$ and $61 \%$ respectively. The most sensitive antibiotics were colistin, tigecycline, imipenem and meropenem. In the present study, 73\% (47) of the isolates were resistant to at least three to fourteen antibiotics. All the isolates showed resistance to at least one antibiotic. Thirtynine per cent of $E$. coli isolates were extended spectrum beta-lactamase (ESBL) producers.

Conclusion: Considering the antibiogram, imipenem and meropenem should be preferred drugs for E. coli infection isolated from clinical samples.
\end{abstract}

Key words: Esherichia coli, antibiotic sensitivity, clinical specimens, intensive care unit

Suggested Citation: Cebeci T, Keskin D, Gökal AA. Produce Extended Spectrum Beta-Lactamase Strains Isolated from Various Clinical Specimens in Intensive Care Unit. Middle Black Sea Journal of Health Science, 2019; 5(1): 33-38

Address for correspondence/reprints:

Tuğba Cebeci

Telephone number: +90 (454) 3101430

E-mail: tgbcbcdmn@gmail.com

DOI: $10.19127 / \mathrm{mbsjohs} .525833$

\section{Introduction}

Esherichia coli is a diverse group of facultative anaerobic Gram-negative bacilli of the genus Escherichia in the family Enterobacteriaceae, and contains a variety of strains ranging from commensal organisms to highly pathogenic variants especially the intestine and the urinary tract (Mos et al., 2010).

The extended spectrum beta-lactamase (ESBL) enzymes are predominantly found in $E$. coli and Klebsiella spp. however, may also be found in other 
species of Enterobacteriaceae (Khanfar et al., 2009). Fluoroquinolones, aminoglycosides and trimethoprim-sulfamethoxazole are used for treatment of infections caused by ESBL- producing bacteria (Falagas and Karageorgopoulos., 2009).

The aim of this study was to determine the characteristics and patterns of antibiotic resistance among isolates of $E$. coli recovered from clinical specimens in Giresun province.

\section{Methods}

\section{Bacterial isolates}

Ethical approval is were taken before study. Because of retrospective analysis, we did not patient approval. The sixty four $E$. coli were isolated from clinical specimens from intensive care unit of internal medicine in private hospital. Bacterial isolates were identified to level of species and subspecies by using the morphological and traditional biochemical tests and automatic diagnostic systems currently present in the market and commonly used for AST (Antimicrobial Susceptibility Testing) in clinical laboratories will therefore have to incorporate these criteria in their instruments to meet the needs of European microbiology laboratories according to standard methods described by (MacFaddin., 2000). In total, $64 \mathrm{E}$. coli were isolated from various clinical samples and detected by the VITEK 2 (bioMérieux) at the microbiology laboratory of our hospital between from January in 2017 to December in 2018. The VITEK 2 Compact Automated Microbiology System (bioMérieux) is designed for the rapid bacterial identification at the species level and determination of AST of clinically significant human bacterial pathogens (Ling et. al., 2001).

\section{Antibiogram profile of $E$. coli}

MIC results previously obtained in recent clinical isolates with well-defined in isolates with well-characterized resistance mechanisms with microdilution method were re-interpreted for the susceptible, intermediate and resistant categories using the 2018 EUCAST breakpoints. Fifteen different antibiotics were used. Antibiotics tested in AST-N326 (bioMérieux) card included piperacillin (PIP), ceftazidim (CAZ), aztreonam (ATM), levofloxacin (LEV), cefepime (FEP), trimethoprimsulfamethoxazole (SXT), ciprofloxacin (CIP), tazobactam/piperacillin (TZP), netilmicin (NET), gentamicin (GEN), colistin (CT), amikacin (AK), imipenem (IPM), meropenem (MEM), tigecycline (TIG).

\section{Detection of ESBL}

VITEK 2 system with the antimicrobial susceptibility extend card AST-N326 (bioMérieux) card was designed to perform both screening and confirmatory tests for phenotypic detection of ESBL on the same plate. VITEK 2 system has two different ESBL detection procedures. The first one uses specific computer software called advanced expert system (AES), that performs analyzes and interpretation of MIC of the antibiotics used. The use of several antimicrobial agents increases the sensitivity of ESBL detection (Sorlózano et. Al., 2005) thus the second procedure was based on ESBL test on same AST-N326 card, where the antibiotic susceptibility of the isolates to FEP and 3rd generatin cephalosporin: cefotaxime (CTX) and ceftazidime (CAZ) with or without clavulanic acid were evaluated (Drieux et al., 2008).

\section{Multiple Antibiotic Resistance (MAR) index}

For all isolates, MAR index values were tested according to Matyar et al., (2008).

\section{Results}

The results of resistance pattern of E. coli isolates in our locality to antimicrobial agents showed that the $64 \mathrm{E}$. coli strains tested against fifteen antimicrobial agents in Table 1. E. coli isolates were highly resistant to PIP, CAZ and ATM $98 \%, 61 \%$ and $61 \%$ respectively. Resistance rate of CIP was showed in $52 \%$. When we compared to resistance of TZP, E. coli isolates showed 38\% resistance rate. Among the aminoglycosides group, GEN resistance rate was $28 \%$. In respect of resistance rate of $\mathrm{CT}$, it was $11 \%$. The most sensitive antibiotics were CT, TIG, IPM and MER, as is illustrated in Table 1 and Table 2 shows the antimicrobial susceptibility of all $E$. coli isolated from urine, blood, and sputum. Of the total E. coli isolates, $25(39 \%)$ isolates were ESBL producers and $39(61 \%)$ isolates were non-ESBL producers in Table 2. 
Table 1. Antibiotic resistance pattern of 64 E. coli isolated from clinical specimens in intensive care unit.

\begin{tabular}{lrrr} 
Antibiotics & Resistance & Intermediate & \multicolumn{1}{r}{ Sensitive } \\
\hline PIP & $63(98 \%)$ & - & $1(2 \%)$ \\
CAZ & $39(61 \%)$ & $2(3 \%)$ & $23(36 \%)$ \\
ATM & $39(61 \%)$ & $3(15 \%)$ & $22(34 \%)$ \\
LEV & $36(56 \%)$ & - & $28(44 \%)$ \\
FEP & $34(53 \%)$ & $6(9 \%)$ & $24(38 \%)$ \\
SXT & $34(53 \%)$ & $1(2 \%)$ & $29(45 \%)$ \\
CIP & $33(52 \%)$ & $2(3 \%)$ & $29(45 \%)$ \\
TPZ & $24(38 \%)$ & $37(58 \%)$ & $3(4 \%)$ \\
NET & $22(34 \%)$ & $2(3 \%)$ & $40(63 \%)$ \\
GEN & $18(28 \%)$ & $1(2 \%)$ & $45(70 \%)$ \\
CT & $7(11 \%)$ & - & $57(89 \%)$ \\
AK & $7(11 \%)$ & $10(16 \%)$ & $47(73 \%)$ \\
IPM & $5(7 \%)$ & $9(14 \%)$ & $50(78 \%)$ \\
MEM & $4(6 \%)$ & $9(14 \%)$ & $51(80 \%)$ \\
TIG & $4(6 \%)$ & $4(6 \%)$ & $56(88 \%)$
\end{tabular}

Abbreviation; PIP, Piperacillin, CAZ; Ceftazidim, ATM; Aztreonam, LEV; Levofloxacin, FEP; Cefepime, SXT; Trimethoprim sulfamethoxazole, CIP; Ciprofloxacin, TPZ; Tazobactam/Piperacillin, NET; Netilmicin, GEN; Gentamicin, CT; Colistin, AK; Amikacin, IPM; Imipenem; MEM; Meropenem, TIG; Tigecycline.

\section{Discussion}

In our study, when we compared to resistance of PIP, E. coli isolates showed high antibiotic resistance with 98\% PIP. Some researchers have reported resistance rate PIP from $100 \%$ to $17.2 \%$ to E. coli in clinical samples (Kafilzadeh and Farsimadan., 2016; Batarseh et al., 2013). Our results were lower than Batarseh et al., (2013) who also reported that resistance rate of PIP with $100 \%$.

When it comes to resistance of CAZ, E. coli isolates showed high antibiotic resistance with $61 \%$ CAZ. Some researchers have reported that CAZ resistance rate from $7.3 \%$ to $98.9 \%$ to $E$. coli in clinical samples (Ozsahin et al., 2005; Al-Mijali et al., 2017). Our results were lower than Al-Mijali et al., (2017) who also reported that resistance rate of CAZ with $98.9 \%$.

In our study, when we compared to resistance of ATM, E. coli isolates showed high antibiotic resistance with $61 \%$ ATM. Some researchers have reported that ATM resistance rate from $89 \%$ to 98.9\% to E. coli in clinical samples (Akter et al., 2012; Al-Mijali et al., 2017). Our results were lower than Akter et al., (2012) who also reported that resistance rate of ATM with $89 \%$.

Table 2. Distribution of 64 E. coli clinical samples, Sexuality, source, MAR Index and ESBL Producers

\begin{tabular}{|c|c|c|c|c|c|}
\hline Name of Clinic & $\begin{array}{l}\text { Number } \\
\text { of samples }\end{array}$ & Source of isolates & $\begin{array}{l}\text { Sexuality } \\
\text { F/M }\end{array}$ & $\begin{array}{l}\text { ESBL } \\
\text { Producers }\end{array}$ & MAR İndex \\
\hline $\begin{array}{l}\text { Anesthesia and } \\
\text { Reanimation }\end{array}$ & 34 & $\begin{array}{l}5 \text { Sputum } \\
29 \text { Urine }\end{array}$ & $18 \mathrm{~F} 16 \mathrm{M}$ & $\begin{array}{l}21- \\
12+\end{array}$ & $\begin{array}{l}0.07(8 \text { isl }) ; 0,14(2 \text { isl }) ; 0.2(4 \text { isl }) ; \\
0.27 ; 0.33 ; 0.4(7 \text { isl }) ; 0.47 ; 0.53(3 \text { isl }) ; 0 \\
.87 ; 0.67 ; 0.6(2 \text { isl }) ; 0.8(2 \text { isl }) ; 0,93\end{array}$ \\
\hline Internal medicine & 9 & 9 Urine & $9 \mathrm{~F}$ & $\begin{array}{l}6+ \\
3- \\
3-\end{array}$ & $\begin{array}{l}0.07 ; 0.14 ; 0.47 ; 0.53 \text { (3 isl) } 0.6 \text {; } \\
0.67 \text { (2isl) }\end{array}$ \\
\hline Chest diseases & 6 & $\begin{array}{l}2 \text { Sputum } \\
\text { 4Urine }\end{array}$ & $4 \mathrm{~F} 2 \mathrm{M}$ & $\begin{array}{l}2- \\
4+\end{array}$ & $0.2 ; 0.27 ; 0.33(2) ; 0.6 ; 0.67$ \\
\hline Neurology & 7 & $\begin{array}{l}2 \text { Sputum } \\
\text { 5Urine }\end{array}$ & $3 \mathrm{~F} 4 \mathrm{M}$ & $\begin{array}{l}5- \\
2+\end{array}$ & $0.07 ; 0.27 ; 0.4 ; 0.47 ; 0.53(2) ; 0.67$ \\
\hline $\begin{array}{l}\text { Infectious } \\
\text { Diseases }\end{array}$ & 2 & 2Urine & $1 \mathrm{M} 1 \mathrm{~F}$ & $2-$ & $0.07(2$ isl $)$ \\
\hline Cardiology & 3 & 1Blood & $3 \mathrm{M}$ & $\begin{array}{l}1+ \\
2-\end{array}$ & $0 . \quad 0.4 ; 0.93$ \\
\hline Gynecology & 1 & 1Urine & $1 \mathrm{~F}$ & & 0.07 \\
\hline General Surgery & 1 & 1Urine & & $1-$ & 0.8 \\
\hline $\begin{array}{l}\text { Brain and Nerve } \\
\text { Diseases }\end{array}$ & 1 & 1 Sputum & $1 \mathrm{~F}$ & $1-$ & 0.07 \\
\hline Total & 64 & $\begin{array}{l}53 \text { Urine, } \\
10 \text { Sputum } \\
1 \text { Blood }\end{array}$ & & $\begin{array}{l}25+(39 \%) \\
39-(61 \%)\end{array}$ & \\
\hline
\end{tabular}

MAR, Multiple Antibiotic Resistance Index, isl; 1solates, +; ESBL Producing, -Non-ESBL Producing F; Female, M; Male 
In our study, when we compared to resistance of LEV, E. coli isolates showed high antibiotic resistance with 56\% LEV. Some researchers have reported resistance rate LEV from $63,23 \%$ to $82 \%$ (Sohail et al., 2015; Al-Mijali et al., 2017). Our results were lower than Al-Mijali et al., (2017) who also reported that resistance rate of LEV with $63.23 \%$ to E. coli in clinical samples.

As for the resistance rate of FEP to E. coli islates it showed high resistance with 53\%, Some researchers have reported resistance rate from $4,1 \%$ to $47.5 \%$ FEP to $E$. coli in clinical samples (Albayrak and Kaya, 2009; Batarseh et al., 2013). Our results were higher than Batarseh et al., (2013) who also reported that resistance rate of FEP with $47.5 \%$ to $E$. coli in clinical samples.

As for the resistance rate of $\mathrm{AK}$, it was $11 \%$. Some researchers have reported that $\mathrm{AK}$ resistance rate from $21.2 \%$ to $91 \%$ to $E$. coli in clinical samples (Albayrak and Kaya, 2009; Sohail et al., 2015). In other studies which conducted in Italy (Tinelli et al., 2012), Brazil (Abreu et al., 2011), and Nepal (Chander et al., 2013), the resistance rates were lower compared to our results.

Being a highly beta-lactamase stable carbapenem, with an unusual property of causing a post antibiotic effect on Gram negative bacteria resistance to IPM was found to be very low (7\%). On the other hand, higher resistances were shown by (Jafri et al., 2014) and (Sabir et al., 2014) were $43.3 \%$ and $32.5 \%$ respectively. Some researchers have reported that IPM resistance rate to E. coli in clinical samples (Al-Mijali et al., 2017).

Carbapenems, especially MEM, resistance rate of MEM was showed in $6 \%$ (table1). Some researchers have reported that MEM from 3\% to $1.20 \%$ resistance rate to $E$. coli in clinical samples (Sohail et al., 2015; Al-Mijali et al., 2017). Our results were higher than Sohail et al., (2015) who also reported that resistance rate of MEM with 3\%.

In our study, when we compared to resistance of TIG, E. coli isolates showed antibiotic resistance with $6 \%$ TIG. Some researchers have reported that TIG from $6.59 \%$ to $9.8 \%$ resistance rate to $E$. coli in clinical samples (Batarseh et al., 2013; Al-Mijali et al., 2017). Our results were equavalent to Al-Mijali et al., (2017) who also reported that resistance rate of TIG with $6,59 \%$.

As for the ESBL producers, our results were similiar to El Sayed et al. (2017) who also reported that out of 100 isolates of E. coli, 36 were detected as ESBL producers and 64 were non-ESBL producers. In studies performed throughout the world, the frequency of ESBL positive. E. coli was from $0.2 \%$ to $95.4 \%$ (Shadid et al., 2008; Kaftandzhieva et al., 2009). For example, in a study Tasli ve Bahar, in Turkey producing ESBL enzymes in Escherichia coli strains of $17 \%$, in the study Villegas, in Colombia 3.3-4.7\% (Villegas et al., 2004), in the study Duttaroy and Mehta (2005), in India $29.1 \%$ in study Lavigne et al., (2004), in France $16.2 \%$, have been reported.

On the other hand, study of Zhou, in Shanghai show that $47.4 \%$ of $E$. coli isolated from patients were ESBL producers (Zhou., 2001), in another study by the $\mathrm{Wu}$, be was conducted in Taiwan hospitals, a rate of $18.18 \%$ of ESBL-producing $E$. coli (Wu et al., 2003), While in Lebanon the amount of at 28.1 percent, respectively (Daoud and Hakime, 2003).

In the present study, 73\% (47) of the isolates showed Multiple Antibiotic Resistance three to fourteen antibiotics. All of the isolates showed resistance to at least one antibiotics.

The antimicrobial resistance of bacteria is a problem of global concern. There is a correlation between antibiotic use and subsequent resistance (Jensen et al., 2009). In the present study, it was observed that the isolates of $E$. coli showed different degree of resistance to different antimicrobials. The samples were isolated from different clinical specimens. Maximum numbers of isolates were collected from urine indicating that urinary tract is more prone to infection by $E$. coli which corresponds to the findings of other researchers (Sharafi et al., 1996; Paterson and Bonomo., 2005; Kumar et al., 2014).

\section{Conclusion}

Considering the antibiogram, CT, TIG, IPM and MER should be preferred drugs for $E$. coli infection isolated from clinical samples from Giresun region.

Ethics Committee Approval: Patients' consent was obtained in the use of microbiological data.

Peer-review: Externally peer-reviewed.

Author Contributions: Concept -T.C., D.K.;Design-T.C, D.K;Supervision A.A.G; Materials- A.A.G; Data Collection and/or Processing- A.A.G.; Analysis and/or InterpretationT.C., D.K.; Literature Review - T.C., D.K., A.A.G; Writing - T.C, D.K. ; Critical Review - T.C., D.K., A.A.G.

Conflict of Interest: No conflict of interest was declared by the authors.

Financial Disclosure: The authors declared that this study hasn't received no financial support. 


\section{References}

Abreu AG, Marques SG, Monteiro-Neto V, Carvalho RM, Goncalves AG. Nosocomial infection and characterization of extendedspectrum beta-lactamases-producing Enterobacteriaceae in Northeast Brazil. Rev Soc Bras Med Trop. 2011; 44(4) :441-6.

Akter FM, Hossain MM, Rahman A, Shaha M, Amani Ael A. Antimicrobials Resistance Pattern of Escherichia coli Collected from Various Pathological Specimens. Pakistan Journal of Biological Sciences 2012; 15: 1080-1084.

Albayrak N, Kaya S. Extended spectrum beta lactamases production and antimicrobial resistance ratio of the Esherichia coli and Klebsiella pneumoniae strains isolated from various clinical specimens. Turkish Society of Microbiology Journal 2009; 39: 16-21.

Al-Mijalli SHS. Bacterial Uropathogens in Urinary Tract Infection and antibiotic susceptibility pattern in Riyadh Hospital, Saudi Arabia. Cell Mol Med 2017, 3:1.

Batarseh A, Soneah S, Mardeni R, Elmadni K, Noor M, Ashour NA. Antibiotic resistance patterns of multidrug resistant and extended-spectrum $\beta$ lactamase producing Esherichia coli urinary isolates at queen Rania al-abdullah hospital for children. Jordan Z U M J. 2013;19(5):286-93.

Chander A, Shrestha CD. Prevalence of extended spectrum beta lactamase producing Escherichia coli and Klebsiella pneumoniae urinary isolates in a tertiary care hospital in Kathmandu, Nepal. BMC ResNotes 2013; 6:487. doi: 10.1186/17560500-6-487.

Daoud Z, Hakime N. Prevalence and susceptibility patterns of extended-spectrum betalactamaseproducing Escherichia coli and Klebsiella pneumoniae in a general university hospital in Beirut, Lebanon. Rev Esp Quimioter 2003; 16(2): 233-8.

Drieux L, Brossier F, Sougakoff W, Jarlier V. Phenotypic detection of extended spectrum $\beta$ lactamase production in Enterobacteriaceae: review and bench guide. Clin. Microbiol. Infect. 2008;14(Suppl 1): 90-103.

Duttaroy B, Mehta S. Extended spectrum betalactamases (ESBL) in clinical isolates of Klebsiella pneumoniae and Escherichia coli. Indian J Pathol Microbiol 2005; 48: 45-8.

Elsayed TI, Ismail HA, Elgamal SA. The Occurrence of Multidrug Resistant E. coli which Produce ESBL and Cause Urinary Tract Infections. J Appl Microbiol Biochem. 2017; 1: 2-8.
Falagas ME, Karageorgopoulos DE. Extendedspectrum betalactamase-producing organisms. J Hosp Infect. 2009; 73(4): 345-54.

Jafri SA, Qasim M, Masoud MS. Antibiotic resistance of $E$. coli isolates from urine samples of urinary tract infection (UTI) patients in Pakistan. Bioinformation 2014; 10: 419-422.

Jensen US, Skjot-Rasmussen L, Olsen SS, FrimodtMoller N, Hammerum AM, on behalf of the DANRES Study Group. Consequences of increased antibacterial consumption and change in pattern of antibacterial use in Danish hospitals. J Antimicrob Chemother 2009; 63: 812-815

Kafilzadeh F, Farsimadan F. Investigating multidrug efflux pumps in relation to the antibiotic resistance pattern in Escherichia coli strains from patients in Iran. Biomedical Research 2016; 27 (4): 1130-1135.

Kaftandzhieva A., Kotevska V, Jankoska G. Extended-spectrum beta-lactamase- producing E. coli and Klebsiella pneumoniae in children at University pediatric clinic in Skopje. Macedonian J Med Sci 2009; 2(1): 36-41.

Khanfar HS, Bindayna KM, Senok AC, Botta GA. Extended spectrum beta-lactamases (ESBL) in Escherichia coli and Klebsiella pneumoniae: trends in the hospital and community settings. $\mathrm{J}$ Infect Dev Ctries 2009; 3(4):295-9.

Kumar D, Singh AK, Ali MR, Chander Y. Antimicrobial Susceptibility Profile of Extended Spectrum $\beta$-Lactamase (ESBL) Producing Escherichia coli from Various Clinical Samples. Infectious Diseases: Research and Treatment 2014;7:1-8.

Lavigne JP, Bouziges N, Chanal C, Mahamat A, Michaux-Charachon S, Sotto A. Molecular epidemiology of Enterobacteriaceae isolates producing extended-spectrum beta-lactamases in a French hospital. J ClinMicrobiol 2004; 42: 3805-8.

Ling TK, Tam PC, Liu ZK, Cheng AF. Evaluation of VITEK 2 rapid identification and susceptibility testing system against gramnegative clinical isolates. J. Clin. Microbiol. 2001; 39: 2964-6.

MacFaddin FJ. Biochemical Tests for Identification of Medical Bacteria., 3rd Edn., Philadelphia, USA, 2000 p. 912.

Matyar F, Kaya A, Dinçer S. Antibacterial agents and heavy metal resistance in Gram-negative bacteria isolated from seawater, shrimp and sediment in Iskenderun Bay, Turkey. Science Total and Environment 2008; 407: 279-285. 
Mos I, Micle O, Zdrâncă M, Mureșan M, Vicaș L. Antibiotic Sensitivity of the Escherichia coli Strains Isolated from Infected Skin Wounds. Farmacia 2010; 58 (5): 637-44.

Ozsahin D, Digrak M, Kiran OE. The Investigation on resistance Properties of Esherichia coli against Beta Lactam Groups Antibiotics. KSU, Journal Of science and Engineering 2005;8(2):812.

Paterson DL, Bonomo RA. Extended-spectrum $\beta$ lactamases: a clinical update. Clin Microbiol Rev, 2005; 18:657-686.

Sabir S, Anjum AA, Ijaz T. Isolation and antibiotic susceptibility of E. coli from urinary tract infections in a tertiary care hospital. Pak J Med Sci. 2014; 30(2):389-92.

Shahid, M., Malik, A., Akram, M. Prevalent phenotypes and antibiotic resistance in Escherichia coli and Klebsiella pneumonia at an Indian tertiary care hospital: plasmid-mediated cefoxitin resistance. Int J Infect Dis, 2008;12(3): 256-64.

Sharafi R, Ceckler R, Childs S. Treatment of urinary tract infections: Selecting an appropriate broadspectrum antibiotic for nosocomial infections. Am. J. Med., 1996; 100: 76-82.

Sohail M, Khurshid M, Saleem HGM, Javed H, Khan AA. Characteristics and Antibiotic Resistance of Urinary Tract Pathogens Isolated from Punjab, Pakistan, Jundishapur J Microbiol. 2015; 8(7): e19272.

Sorlózano A, Gutiérrez J, Piédrola G, Soto MJ. Acceptable performance of VITEK 2 system to detect extended-spectrum beta-lactamases in clinical isolates of Escherichia coli: a comparative study of phenotypic commercial methods and NCCLS guidelines. Diagn Microbiol Infect Dis 2005;51:191-3.

Tasli H, Bahar IH. Molecular characterization of TEM- and SHV-derived extended spectrum beta-lactamases in hospital-based Enterobacteriaceae in Turkey. Jpn J Infect Dis. 2005; 58(3): 162-7.

Tinelli M, Cataldo MA, Mantengoli E, Cadeddu C, Cunietti E, Luzzaro F, et al. Epidemiology and genetic characteristics of extended-spectrum beta-lactamase-producing Gram-negative bacteria causing urinary tract infections in longterm care facilities. J Antimicrob Chemother. 2012; 67(12):2982-7.
Villegas, M.V., Correa, A., Perez, F., Miranda, MC., Zuluaga, T., Quinn, JP. Prevalence and characterization of extended-spectrum betalactamases in Klebsiella pneumoniae and Escherichia coli isolates from Colombian hospitals. DiagnMicrobiol Infect Dis. 2004; 49(3): 217-22.

Wu TL, Chia JH, Su LH, Kuo AJ, Chu C, Chiu CH. Dissemination of extended-spectrum betalactamase-producing Enterobacteriaceae in pediatric intensive care units. J ClinMicrobiol. 2003; 41(10): 4836-8.

Zhou L. Pathogens and associated factors of infections in PICU. Shanghai second medical university afflicted shanghai children medical center. 2001. 